This document is the accepted manuscript version of the following article:

Srna, A., Bolla, M., Wright, Y. M., Herrmann, K., Bombach, R., Pandurangi, S. S., ... Bruneaux, G. (2019). Effect of methane on pilotfuel auto-ignition in dual-fuel engines. Proceedings of the Combustion Institute, 37(4), 4741-4749. https://doi.org/10.1016/ j.proci.2018.06.177

This manuscript version is made available under the CC-BY-NC-ND 4.0

license http://creativecommons.org/licenses/by-nc-nd/4.0/

Title:

\title{
Effect of methane on pilot-fuel auto-ignition in dual-fuel engines
}

Authors:

Aleš Srna ${ }^{\mathrm{a}, 1}$, Michele Bolla ${ }^{\mathrm{b}}$, Yuri M. Wright ${ }^{\mathrm{b}}$, Kai Herrmann ${ }^{\mathrm{c}}$, Rolf Bombach ${ }^{\mathrm{a}}$, Sushant S. Pandurangi ${ }^{\mathrm{b}}$, Konstantinos Boulouchos ${ }^{\mathrm{b}}$, Gilles Bruneaux ${ }^{\mathrm{d}}$

${ }^{a}$ Thermal Processes and Combustion Laboratory, Paul Scherrer Institute, CH-5232 Villigen PSI, Switzerland

${ }^{\mathrm{b}}$ Aerothermochemistry and Combustion Systems Laboratory, Swiss Federal Institute of Technology, Zurich, Switzerland

${ }^{c}$ Institute of Thermal and Fluid Engineering, School of Engineering, University of Applied Sciences and Arts Northwestern Switzerland

${ }^{d}$ IFP Energies nouvelles, 1 et 4 avenue de Bois Préau, 92852 Rueil-Malmaison, France; Institut Carnot IFPEN Transports Energie

Colloquium: Internal Combustion Engines

Word count using method 1:

Main text: $\quad \underline{4428 \text { words }}$

References: $\quad(26$ References +2$) * 2.3$ lines/reference $* 7.6$ words $/$ line $=\underline{489 \text { words }}$

Figures: $\quad$ Figure 1: 132, Figure 2: 156, Figure 3: 259, Figure 4: $323=\underline{870 \text { words }}$

Total: $\quad \mathbf{5 7 8 7}$ words

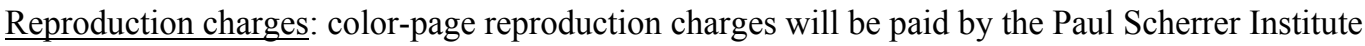

${ }^{1}$ Corresponding author:

Aleš Srna

Paul Scherrer Institute

Thermal Processes and Combustion Laboratory

OVGA 119/A

CH-5232 Villigen PSI

Switzerland

email: ales.srna@psi.ch 


\section{List of Figure captions:}

Figure 1: $\quad$ Schematic of the RCEM geometry and optical arrangement for simultaneous $\mathrm{CH}_{2} \mathrm{O}-\mathrm{PLIF} \mathrm{OH}^{*}$ and Schlieren imaging.

Figure 2: $\quad$ Low-T (dashed) and high-T (full line) ID dependency on $\phi_{\mathrm{CH} 4}$ and $\mathrm{T}_{\mathrm{SOI}}$. Error bars show the standard deviation of the high-T ID.

Figure 3: Raw $\mathrm{CH}_{2} \mathrm{O}$-LIF image time sequence, dashed black/white contour denote jet boundary detected by Schlieren. Red contour shows regions with detected $\mathrm{OH}^{*}$. Conditions: $\mathrm{T}_{\mathrm{SOI}}=770 \mathrm{~K} / \phi_{\mathrm{CH} 4}=0$ (left), $\mathrm{T}_{\mathrm{SOI}}=850 \mathrm{~K} / \phi_{\mathrm{CH} 4}=0.66$ (right)

Figure 4: Influence of methane addition on two-stage ignition using HR calculations (left). 1D-flamelet results presented in the form of reaction rate of $\mathrm{CH}_{2} \mathrm{O}$ for a diesel (centre) and dual-fuel case with similar ID (right). The temporal evolution of the maximal $\phi_{\mathrm{nC} 12}$ available is drawn as dotted line. Orange and green lines present low-T and high-T ID at different imposed SDR evolutions (shown in the inlay plot on the right). 
Title: Effect of methane on pilot-fuel auto-ignition in dual-fuel engines

\section{Authors:}

A. Srna, M. Bolla, Y. M. Wright, K. Herrmann, R. Bombach, S. S. Pandurangi, K. Boulouchos, G. Bruneaux

\section{Abstract:}

The ignition behavior of $n$-dodecane micro-pilot spray in a lean-premixed methane/air charge was investigated in an optically accessible Rapid Compression-Expansion Machine at dual-fuel engine-like pressure/temperature conditions. The pilot fuel was admitted using a coaxial single-hole $100 \mu \mathrm{m}$ injector mounted on the cylinder periphery. Optical diagnostics include combined high-speed $\mathrm{CH}_{2} \mathrm{O}$-PLIF $(10 \mathrm{kHz})$ and Schlieren $(80 \mathrm{kHz})$ imaging for detection of the firststage ignition, and simultaneous high-speed $\mathrm{OH}^{*}$ chemiluminescence $(40 \mathrm{kHz})$ imaging for high-temperature ignition. The aim of this study is to enhance the fundamental understanding of the interaction of methane with the auto-ignition process of short pilot-fuel injections. Addition of methane into the air charge considerably prolongs ignition delay of the pilot spray with an increasing effect at lower temperatures and with higher methane/air equivalence ratios. The temporal separation of the first $\mathrm{CH}_{2} \mathrm{O}$ detection and high-temperature ignition was found almost constant regardless of methane content. This was interpreted as methane mostly deferring the cool-flame reactivity. In order to understand the underlying mechanisms of this interaction, experimental investigations were complemented with 1D-flamelet simulations using detailed chemistry, confirming the chemical influence of methane deferring the reactivity in the pilot-fuel lean mixtures. This shifts the onset of first-stage reactivity towards the fuel-richer conditions. Consequently, the onset of the turbulent cool-flame is delayed, leading to an overall increased high-temperature ignition delay. Overall, the study reveals a complex interplay between entrainment, low- $\mathrm{T}$ and high- $\mathrm{T}$ chemistry and micro-mixing for dual-fuel autoignition processes for which the governing processes were identified.

\section{Keywords:}

Dual-fuel combustion, auto-ignition, $\mathrm{CH}_{2} \mathrm{O}$-PLIF, turbulence-chemistry interaction, cool-flame

\section{Introduction}

Combustion of lean premixed natural gas in internal combustion engines is attracting considerable attention as an alternative to diesel operation due to significantly reduced particulate and $\mathrm{NO}_{\mathrm{x}}$ emissions at comparable efficiencies While favorable from a knock resistance perspective, the low reactivity renders reliable ignition of lean premixed charges very difficult. Aside pre-chamber ignition systems widely used for lean premixed natural gas/air combustion in engines, ignition by means of a micro-pilot injection of a high-cetane liquid fuel constitutes an interesting alternative to ensure successful combustion initiation. Various studies using such "dual-fuel" approaches are documented, reporting a tradeoff 3 
between low emissions of unburnt hydrocarbons and low emissions of $\mathrm{NO}_{\mathrm{x}}$ and soot. Higher portions of pilot fuel improve complete combustion of the premixed fuel but strongly increase soot and $\mathrm{NO}_{\mathrm{x}}[1,2]$. With shorter pilot injections, engine performance can deteriorate due to the high sensitivity of ignition delay (ID) to changes in concentration of premixed methane [1], leading to large heat release fluctuations and possible misfire. Improved understanding of the impact natural gas exhibits on the pilot fuel ignition process is therefore of paramount importance to reliably control ignition in lean-burn premixed. Aside full-metal engine investigations, only few experimental studies are reported with optical access allowing for further detailed characterization of dual-fuel combustion. This is predominantly due to the fact that many conventional constant-volume combustion rigs cannot use premixed charges due to the precombustion event required to reach engine-relevant conditions. Experiments are however reported for optical engines and Rapid Compression (Expansion) Machines, RC(E)M, e.g. [3-7] and references therein. These optical investigations of dual-fuel combustion mostly focused on the detection of ID [6, 7], flame luminosity [3-5, 7] and sooting propensity [4]. A common feature observed is the considerable prolongation of the pilot fuel ID in the presence of methane in the compressed charge [2, 5-7].

Recently fundamental aspects of two-stage auto-ignition of fuels under diesel-engine conditions have received considerable attention, both experimentally in constant-volume chambers [8] and numerically for droplet autoignition [9] and auto-igniting jets [10]. The interaction of low-T and high-T ignition with turbulence was studied in detail $[10,11]$. Both the low-T and high-T ignition in fuel-rich conditions were seen to be considerably accelerated compared to homogeneous reactor (HR) counterparts due to the turbulence-governed transport of radicals and heat from very lean (and therefore hotter) regions. This process was denoted as 'cool-flame wave' as presented in [11]. In the context of fundamental numerical dual-fuel ignition only few studies exist: specifically, the ignition and transition to a premixed flame of a $n$-heptane/methane-air mixture were studied for a laminar mixing layer [12] and for $n$-heptane droplets in homogeneous isotropic turbulence [13]. Nonetheless, the understanding of the effect of methane on the autoignition mechanism is still rather limited.

The scope of this investigation is to shed light on the fundamental ignition characteristics of pilot-injections in dual-fuel applications. Two aspects are different compared to previous diesel-type two-stage auto-ignition studies: (1) short injection duration, and (2) methane-containing oxidizer. The first results in a positive dwell (ignition occurs after End Of Injection, EOI) and progressive leaning-out of the mixture while the second leads to differences in chemical behavior. Optical diagnostics involving simultaneous high-speed $\mathrm{CH}_{2} \mathrm{O}-\mathrm{PLIF}$, line-of-sight hydroxyl chemiluminescence $\left(\mathrm{OH}^{*}\right)$ and Schlieren imaging complemented with dedicated HR and 1D-flamelet calculations have been applied to provide fundamental insights w.r.t. the influence of methane and its interaction with mixing on the auto-ignition process. To the 
authors' best knowledge, this is the first study to analyze experimentally and numerically the relation between the two stages of ignition for dual-fuel combustion.

\section{Experimental setup}

\subsection{The rapid compression-expansion machine (RCEM)}

An optically accessible RCEM with cylinder bore of $84 \mathrm{~mm}$, flat piston and maximal stroke of $249 \mathrm{~mm}$ was used to compress methane/air charge and achieve engine-like conditions. A detailed description of the machine is available in [14].

The combustion chamber was designed to provide a maximal unobstructed path to enable studying of single pilot sprays. A solenoid injector with a $100 \mu \mathrm{m}$ single conical coaxial nozzle was mounted on the cylinder periphery $(5 \mathrm{~mm}$ below the flat cylinder head, $42.5 \mathrm{~mm}$ from the cylinder axis and inclined $5^{\circ}$ towards the piston). Methane/air mixture was conditioned in the combustion chamber by injecting methane after the air filling process was completed. Rapid compression was initiated after sufficient time for mixing of methane. Charge boundary conditions were carefully investigated: flow conditions are nearly-quiescent throughout the cycle [14] and homogeneity of methane/air mixture equivalence ratio (standard deviation $\sigma=0.067$ ) was confirmed by application of tracer-PLIF. Charge temperature is precisely controlled to ensure high temperature homogeneity $(\sigma=3 \mathrm{~K})$ before compression [6].

\subsection{Experimental conditions}

The RCEM was operated with a compression ratio of 20 and 1.2bar charge pressure before compression. At hydraulic Start of Injection (SOI) the pressure was $25 \mathrm{bar}$ and the temperature $\mathrm{T}_{\mathrm{SOI}}=770,810$ and $850 \mathrm{~K}$, at cylinder wall temperatures of 343, 363 and 383K. Cylinder charge consisted of air mixed with different concentrations of methane change of $\mathrm{T}_{\mathrm{SOI}}$ caused by the change of charge isentropic coefficient was estimated $<6 \mathrm{~K}$ and was neglected in the further study.

$n$-Dodecane was used as a non-fluorescing diesel-surrogate pilot fuel. Injection parameters were kept constant: 600bar pressure, $580 \mu$ s hydraulic duration, total injected mass $1.18 \mathrm{mg}$.

A total of ten repetitions have been carried out for all operating conditions.

\subsection{Optical diagnostics}

Optical access into the RCEM combustion chamber is provided along the piston axis through $52 \mathrm{~mm}$ diameter windows in the cylinder head and piston. Laser sheet access is offered by an additional $36 \mathrm{~mm}$ window, mounted in the cylinder head diametrical to the injector. The layout of the optical setup is sketched in Figure 1. High-speed imaging of $\mathrm{CH}_{2} \mathrm{O}-$ PLIF, Schlieren and $\mathrm{OH}^{*}$ was employed simultaneously along the same optical axis to temporally resolve low-T and 
high-T ignition of a single combustion event. Low- $\mathrm{T}$ reactivity products were detected by $\mathrm{CH}_{2} \mathrm{O}-\mathrm{PLIF}$ and high-T ignition by $\mathrm{OH}^{*}$, while Schlieren imaging provided information on the spray boundary before ignition. Dichroic mirrors separated short-wavelength $\mathrm{CH}_{2} \mathrm{O}$-PLIF and $\mathrm{OH}^{*}$ signal from the Schlieren beam. All devices were synchronized to the electronic start of injection ( $0.36 \mathrm{~ms}$ before hydraulic SOI).

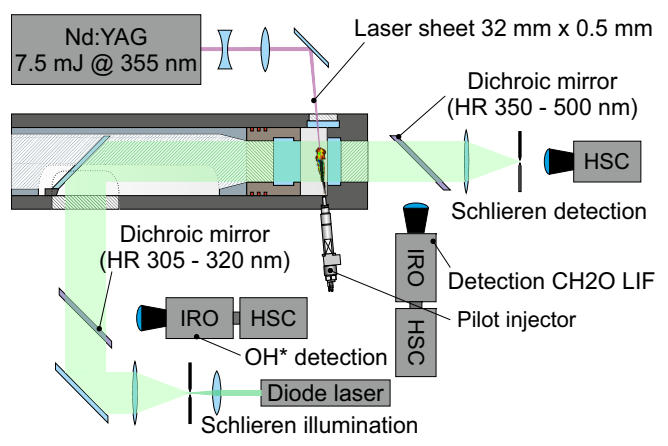

Figure 1: Schematic of the RCEM geometry and optical arrangement for simultaneous $\mathrm{CH}_{2} \mathrm{O}-\mathrm{PLIF}$, $\mathrm{OH}^{*}$ and Schlieren imaging.

\subsubsection{Schlieren}

Schlieren imaging was performed at a frame rate of $80 \mathrm{kHz}$. A fiber-coupled pulsed laser diode (wavelength $690 \mathrm{~nm}$ ) illuminating a ground-glass plate close-coupled to a $1 \mathrm{~mm}$ pinhole was used to generate a point light source. The light was collimated using a $400 \mathrm{~mm}$ focal length achromatic lens and directed along the cylinder axis through the combustion chamber. The collimated beam was refocused using an identical achromatic lens. An aperture was used as Schlieren cutoff at the lens focal point and passing light was detected with a high-speed camera $(1 \mu$ s exposure, $0.16 \mathrm{~mm} /$ pixel projected pixel size). The diameter of the light source and Schlieren cutoff aperture (3mm) were selected to achieve optimal contrast of the images as in comparable studies $[7,8,15]$. Due to hardware obstructions between the RCEM piston and mirror, the region closer than $22 \mathrm{~mm}$ to the injector orifice is not visible.

\subsection{2. $\mathrm{CH}_{2} \mathrm{O}$-PLIF}

The formaldehyde fluorescence was excited at $355 \mathrm{~nm}$ with a $10 \mathrm{kHz}$ diode-pumped Q-switched Nd:YAG laser (Edgewave IS400, 7.5mJ/pulse). A laser sheet was directed towards the injector orifice with inclination of $3.5^{\circ}$ relative to the cylinder head. This optimal position of the laser sheet was determined based on tomographic detection of the ignition location, accounting for fuel-jet compression by the moving piston during the auto-ignition period.

On the detection side, radiation in the wavelength range of $350-500 \mathrm{~nm}$ was separated from the Schlieren beam with a dichroic beamsplitter plate. The bandpass-filtered PLIF signal $(400-480 \mathrm{~nm})$ was detected with an image intensifier coupled to a high-speed camera (projected pixel size $0.11 \mathrm{~mm} /$ pixel); intensifier gate of $100 \mathrm{~ns}$ and 37 counts/photoelectron gain were used. Image flat-field correction was performed based on the tracer-PLIF images of 
homogeneously seeded TMPD vapor in nitrogen atmosphere. The pulse energy fluctuations were corrected by measuring the intensity of a sampled laser beam using a fast photodiode and a SRS Boxcar integrator.

Well-known interference by PAH $[16,17]$ and soot incandescence [18] does not affect low-T ignition detection by the $\mathrm{CH}_{2} \mathrm{O}$-PLIF. Some interference by the fuel-impurities was observed: in the liquid spray region the interference reached up to $15 \%$ of the maximum $\mathrm{CH}_{2} \mathrm{O}$ signal. In the interpretation of results, this interference was distinguished from the $\mathrm{CH}_{2} \mathrm{O}$ signal by the temporal and spatial location criterion. The source of impurities in fuel was attributed to deposits of previously used fuels in the fuel supply system based on fluorescence spectra comparison from samples of fresh $n$-dodecane, $n$-dodecane from the fuel system and diesel. A thorough cleaning of the fuel system improved this issue only temporarily.

Skeen at. al. [8] argued that $\mathrm{CH}_{2} \mathrm{O}-\mathrm{PLIF}$ imaging at $10-12 \mathrm{kHz}$ frame rate does not suffice to reliably capture the low-T ignition event. The conditions of interest of this study result in 2-4 times longer ID than the ECN "Spray-A" [19] and are therefore less stiff regarding the required temporal resolution for ignition detection. A combustion event from the first $\mathrm{CH}_{2} \mathrm{O}$ appearance to high-T ignition was resolved by 4-6 images. The capability of simultaneously applied high-speed Schlieren imaging for the first-stage ignition detection between the $\mathrm{CH}_{2} \mathrm{O}$-PLIF frames was considered [8]. However, under some conditions $\mathrm{CH}_{2} \mathrm{O}$ first appears closer than $22 \mathrm{~mm}$ from the injector in a region not accessible for Schlieren imaging. Therefore we report the first-stage ignition as detected by $\mathrm{CH}_{2} \mathrm{O}-\mathrm{PLIF}$.

\subsection{3. $\mathrm{OH}^{*}$ chemiluminescence}

Chemically excited $\mathrm{OH}^{*}$ in the wavelength range of $313 \pm 13 \mathrm{~nm}$ was acquired at $40 \mathrm{kHz}$ using a second intensified highspeed camera at image resolution of $0.18 \mathrm{~mm} /$ pixel. Intensifier gate was kept at $20 \mu \mathrm{s}$ and gain adapted to the brightness of flame emission under different conditions (9-45 counts/photoelectron). The UV radiation was separated from the Schlieren beam using a $308 \mathrm{~nm} 45^{\circ}$ laser mirror. Contrary to the cross-sectioned $\mathrm{CH}_{2} \mathrm{O}$-PLIF first-stage ignition detection, $\mathrm{OH}^{*}$ imaging records integrated signal along the line-of-sight and detects ignition spots over the whole jet volume.

Chemiluminescence of $\mathrm{CO}_{2}{ }^{*}$ may contribute considerably to the overall $\mathrm{OH}^{*}$ signal, especially under lean conditions at high pressure [20]. However, emission of both species follows the same temporal evolution during the ignition event and therefore their relative contribution plays a minor role. Interference of soot incandescence does not affect the high- $\mathrm{T}$ ignition detection by $\mathrm{OH}^{*}$. 


\section{Numerical methodology}

Unsteady flamelet equations are solved to explore the influence of methane addition on the auto-ignition characteristics and to provide qualitative insight on the various time-scales and combustion modes involved. The Lagrangian flamelet model adopted here is to be interpreted as a first-order approximation framework representing the temporal history of the conditional statistics of a flow cloud as it progresses within the jet until it ignites. Conditional fluctuations in thermochemical states and Scalar Dissipation Rate (SDR) were neglected (first-order closure assumption) but compression heating was included.

The conditional SDR is prescribed with a logarithmic expression from [21] introducing a $Z_{\max }$ dependency, which is derived for a mixing layer with limited fuel availability and ensures the SDR tends to zero at mixture fraction boundaries $\mathrm{Z}=0$ and $\mathrm{Z}=\mathrm{Z}_{\max }$. This is particularly important for the pilot-injection test cases considered here exhibiting positive ignition dwells: at the time of ignition the jet has already undergone a considerable level of large-scale mixing and the most reactive mixture fraction (based on homogeneous reactor calculations, discussed below) has already disappeared and the mixture fraction with the highest reactivity typically coincides with the instantaneous $Z_{\max }$. The prescribed conditional SDR profile is adjusted time-dependently scaled by its value at stoichiometry $\chi_{\mathrm{st}}=<\chi \mid \mathrm{Z}=\mathrm{Z}_{\mathrm{st}}>\left(\mathrm{Z}_{\mathrm{st}}\right.$ based on a n-dodecane/air mixture) representing SDR levels experienced by a cloud around the igniting fluid particle in a Lagrangian sense.

Conditional profiles are initialized applying mixing between $n$-dodecane with different methane-air mass fractions (at $\mathrm{Z}=0$ ) and the temperature was determined by adiabatic mixing based on enthalpies of oxidizer and liquid-phase fuel.

The flamelet model is coupled with the reduced $n$-dodecane chemical mechanism by [22] (130 species and 2323 reactions). The choice of kinetics is motivated by findings reported in [23], constituting a comprehensive assessment of chemical mechanisms focused on $n$-dodecane/methane-air blends at dual-fuel engine conditions, where high-fidelity shock-tube data is scarce.

\section{Results and discussion}

\subsection{Influence of methane on pilot fuel ignition delay}

At diesel engine-like conditions, low reactivity of methane (cetane number $\sim 0$ ) in comparison to $n$-dodecane (cetane number 76) suggests no chemical involvement of premixed methane in the initial stages of $n$-dodecane auto-ignition. Nonetheless, literature suggests a considerable increase of the pilot fuel ID in presence of premixed methane [5-7]. We systematically investigated the methane influence on pilot fuel auto-ignition. Figure 2 presents the dependence of firststage and second-stage ID on methane/air equivalence ratio and $\mathrm{T}_{\mathrm{SOI}}$. Low-T ignition was defined as first appearance of $\mathrm{CH}_{2} \mathrm{O}$-PLIF signal exceeding a threshold of 100 counts (approximately $7 \%$ of maximal intensity in the cycle). 
Interference by fuel fluorescence has been detected and eliminated based on the temporal evolution of $\mathrm{CH}_{2} \mathrm{O}$ signal and presence of liquid spray region. High-T ignition was defined by the $\mathrm{OH}^{*}$ signal exceeding a threshold of 40 counts in area larger than 60pixel ${ }^{2}$. This threshold corresponds to the lowest intensifier gain and was increased proportional to the gain for other cases. Sensitivity analysis of the threshold showed minimal influence on the detected ID. Therefore, both $\mathrm{CH}_{2} \mathrm{O}$-PLIF and $\mathrm{OH}^{*}$ thresholds were set at a minimum value which ensured reliable discrimination of the signal from noise.

We observed up to $50 \%$ prolonged high-T ID in the presence of methane. This influence was found augmented with increasing methane concentration and with decreasing temperature as seen also for $n$-heptane in methane/air in [7]. Low$\mathrm{T}$ reactivity precedes high-T ignition by $400-550$ us for all investigated $\phi_{\mathrm{CH} 4}$. Considering up to $600 \mu$ s prolonged high- $\mathrm{T}$ ID, this indicates that methane most significantly influences the low-T ID ( $70-80 \%$ of the total increase). The effect of methane appears to diminish after onset of low-T reactivity. Same characteristic methane impact on ignition was observed also under additional investigated conditions with variation of the injection duration and charge oxygen content (not shown here).

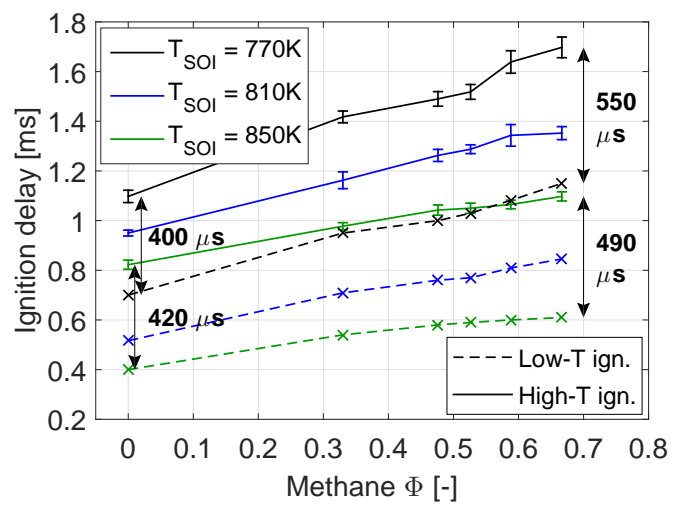

Figure 2: Low-T (dashed) and high-T (full line) ID dependency on $\phi_{\mathrm{CH} 4}$ and $\mathrm{T}_{\mathrm{SOI}}$. Error bars show the standard deviation of the high-T ID.

\subsection{Ignition process in the pilot-fuel jet}

The investigated auto-ignition process is characterized by methane-containing charge and positive ignition dwell. A classical short diesel injection $\left(\mathrm{T}_{\mathrm{SOI}}=770 \mathrm{~K} / \phi_{\mathrm{CH} 4}=0\right)$ and dual-fuel $\left(850 \mathrm{~K} / \phi_{\mathrm{CH} 4}=0.66\right)$ combustion events are compared by means of temporal evolution of $\mathrm{CH}_{2} \mathrm{O}$ distribution. Observed features were similar for the 10 recorded experimental repetitions. Figure 3 illustrates the evolution of $\mathrm{CH}_{2} \mathrm{O}$-PLIF signal overlaid by contours from Schlieren (black/white) and $\mathrm{OH}^{*}$ (red contour) imaging from single combustion events. The high-T ID of chosen cases is nearly the same. $T_{\text {SOI }}$ was increased from 770 to $850 \mathrm{~K}$ to achieve same ID with $\phi_{\mathrm{CH} 4}=0.66$, enabling a comparison of ignition under similar equivalence ratio and turbulence conditions. 


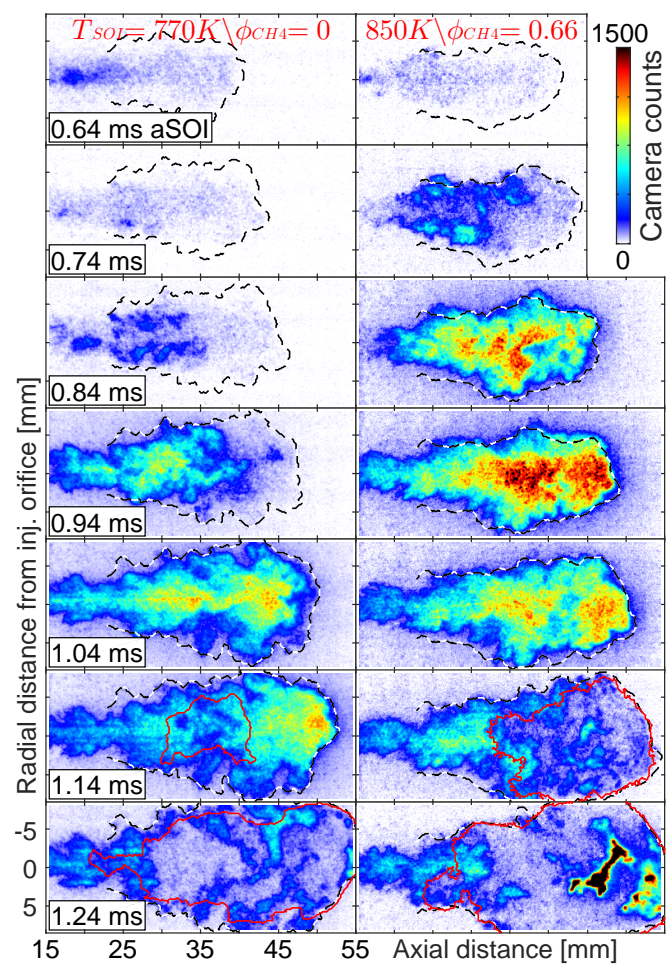

Figure 3: Raw $\mathrm{CH}_{2} \mathrm{O}$-LIF image time sequence, dashed black/white contour denote jet boundary detected by Schlieren. Red contour shows regions with detected $\mathrm{OH}^{*}$. Conditions: $\mathrm{T}_{\mathrm{SOI}}=770 \mathrm{~K} / \phi_{\mathrm{CH} 4}=0$ (left), $\mathrm{T}_{\mathrm{SOI}}=850 \mathrm{~K} / \phi_{\mathrm{CH} 4}=0.66$ (right)

For the diesel case (left panels, $770 \mathrm{~K} / \phi_{\mathrm{CH} 4}=0$ ) initial low-T reactivity is detected at $0.64 \mathrm{~ms}$ at the spray boundary in the wake of the spray head, similarly as reported in [16]. Low-T reactions continue to spread along the jet periphery $(0.74 \mathrm{~ms})$ and towards the spray axis until the whole wake of the jet (except the spray tip) has reacted $(0.84 \mathrm{~ms})$. It takes until $1.14 \mathrm{~ms}$ for the last zones at the spray tip to react, which also coincides with the time of high-T ignition in a zone upstream of the spray tip. Ignition zone corresponds to the spray region which showed an early appearance of high $\mathrm{CH}_{2} \mathrm{O}$ signal at $0.94 \mathrm{~ms}$. The considered diesel case is similar in terms of injection duration (only first injection) and ID studied in [16], where the spray ignition also occurred upstream of the spray tip. Based on the temporally resolved $\mathrm{CH}_{2} \mathrm{O}$ distribution presented here we speculate that ignition takes place upstream of the fuel richest conditions due to the slow spreading rate of the low-T reactivity under the investigated conditions. This is different than in case of a long injection, where strong convection shifts initial low-T reactivity products towards the spray tip and therefore inhibits the low-T reactivity in the upstream regions.

The location of initial low-T reactivity and its spreading along the spray periphery of the dual-fuel case (right panels, $\left.850 \mathrm{~K} / \phi_{\mathrm{CH} 4}=0.66\right)$ is similar as in the diesel case. However, first $\mathrm{CH}_{2} \mathrm{O}$ is detected $100 \mu$ s earlier $(0.64 \mathrm{~ms})$. Comparing the rate of $\mathrm{CH}_{2} \mathrm{O}$-PLIF spreading between $0.64-0.84 \mathrm{~ms}$, the dual-fuel case shows qualitatively faster propagation. Low- $\mathrm{T}$ products reach the spray tip already $0.2 \mathrm{~ms}$ before high- $\mathrm{T}$ ignition at $1.14 \mathrm{~ms}$. Contrary to the diesel case, ignition occurs at the spray tip. At $0.94 \mathrm{~ms}$ lower $\mathrm{CH}_{2} \mathrm{O}$ signal is observed than on previous frame, indicating start of thermal runaway 
over a broad fuel-rich region, confirmed by rising contrast on Schlieren images (not shown). The remaining $\mathrm{CH}_{2} \mathrm{O}$ at $1.14 \mathrm{~ms}$ and $1.24 \mathrm{~ms}$ aSOI is detected in two distinct regions: upstream of the ignition region, $\mathrm{CH}_{2} \mathrm{O}$ signal corresponds to low pilot-fuel equivalence ratio regions in the wake of the jet, similar as reported for a diesel combustion case in an optical engine [18]. In the dual-fuel case PAH-PLIF interference is visible at $1.24 \mathrm{~ms}$ close to the spray tip.

\section{3. $\quad 0 \mathrm{D} / 1 \mathrm{D}$ simulation results}

The influence of methane-addition on the two-stage ignition process is first addressed by means of HR calculations for the cases $\mathrm{T}_{\mathrm{SOI}}=770 \mathrm{~K} / \phi_{\mathrm{CH} 4}=(0 / 0.33 / 0.66)$, cf. Figure 4 (left). These results constitute an important reference for the subsequent analysis including mixing. Low-T ignition timing was determined based on species evolutions according to [24] and for high-T as the time of $80 \%$ reaction progress (based on temperature) [11]. Without methane the mixture exhibits a typical two-stage ignition behavior for lean conditions ( $n$-dodecane equivalence ratio $\phi_{\mathrm{nC} 12}<1.5$ ). Low-T ignition is favored by the hotter gases at very lean conditions and high-T ignition shows its minimum - widely referred to as the most reactive mixture fraction - at slightly rich condition; in line with previous observations, e.g. [10, 11]. The simulations indicate that the addition of methane has an increasingly significant inhibition effect on the low- and high-T chemistry in the dodecane-lean mixture, whereas this effect is reversed for the dodecane-rich mixtures. The most pronounced differences are observed for the earliest low-T ignition, which plays an important role for the subsequent high-T ignition because of transport of chemical species and heat towards richer conditions, discussed below.

The prolonged ID in the presence of methane could potentially be attributed to the increased mixture thermal capacity and to the reduced oxygen partial pressure. The dotted line in Figure 4 (left) refers to $\phi_{\mathrm{CH} 4 \text {,inert }}$ where methane was added as "inert species" to discern the effect of dilution from the chemical effect. Low-T ignition is not influenced whereas high- $\mathrm{T}$ is slightly retarded but to a smaller extent compared to the chemically-active $\mathrm{CH}_{4}$, indicating a chemical involvement of methane in the auto-ignition process. This is consistent with experimental results (see Figure 2), where the increase in ID when adding methane (and therefore reducing oxygen partial pressure) is considerably more pronounced than the empirical relation of Idicheria and Pickett [25] predicts for diesel spray auto-ignition $\left(\mathrm{ID} \propto\left[\mathrm{O}_{2}\right]^{-1}\right)$. For instance, at $\phi_{\mathrm{CH} 4}=0.66$ the relation suggests a $6 \%$ ID increase, whereas measurements in Figure 2 indicate an ID increase between 35 and $55 \%$ for different $\mathrm{T}_{\text {SOI }}$. 

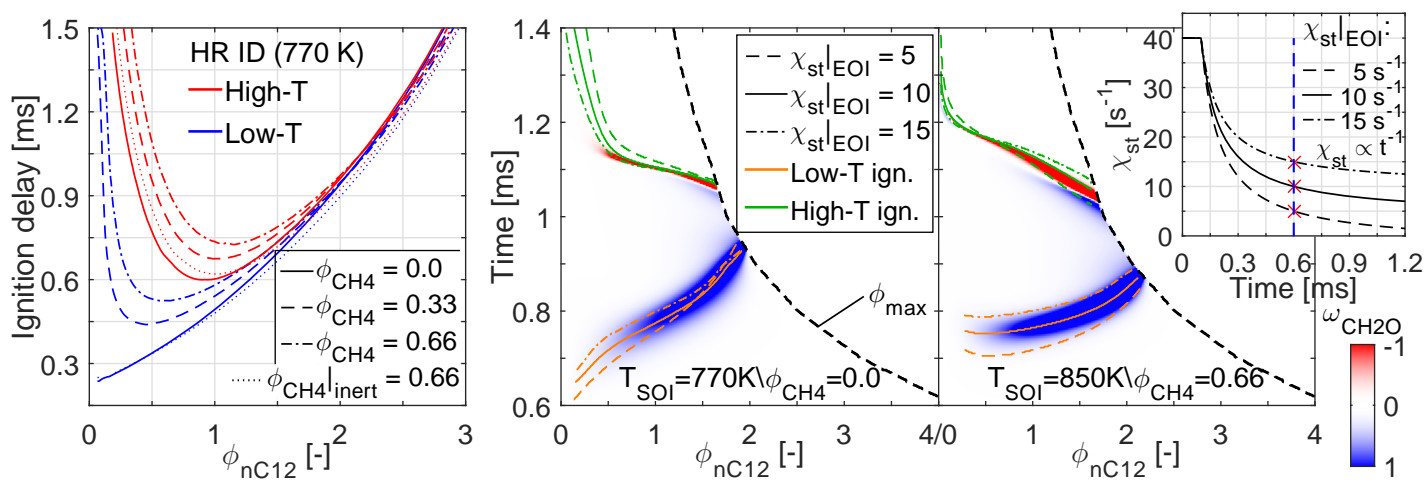

Figure 4: Influence of methane addition on two-stage ignition using HR calculations (left). 1D-flamelet results presented in the form of reaction rate of $\mathrm{CH}_{2} \mathrm{O}$ for a diesel (centre) and dual-fuel case with similar ID (right). The temporal evolution of the maximal $\phi_{\mathrm{nC12}}$ available is drawn as dotted line. Orange and green lines present low-T and high-T ID at different imposed SDR evolutions (shown in the inlay plot on the right).

Results including mixing for the cases shown experimentally in Figure 3 are portrayed in Figure $4\left(\mathrm{~T}_{\mathrm{SOI}}=770 \mathrm{~K} / \phi_{\mathrm{CH} 4}=0\right.$, centre and $\mathrm{T}_{\mathrm{SOI}}=850 \mathrm{~K} / \phi_{\mathrm{CH} 4}=0.66$, right) in form of temporal evolution of $\mathrm{CH}_{2} \mathrm{O}$ reaction rate in $\phi_{\mathrm{nC} 12}$-space. Due to the positive ignition dwell a considerable level of large-scale mixing through entrainment is taking place as discussed above and the maximal mixture fraction $\left(Z_{\max }\right.$ which can be expressed also by $\left.\phi_{\max }\right)$ steadily decreases, cf. dashed black lines in Figure 4 (centre, right). These evolutions were derived from a 1D spray model for the current configuration. The timedependent prescribed value of $\chi_{\mathrm{st}}$ employed to scale the conditional SDR is also illustrated in Figure 4: a constant high value of $40 \mathrm{~s}^{-1}$ is chosen initially mimicking the combined initial physical time delay of rate-of-injection ramp-up and first fuel evaporation. The second important parameter is the value of $\chi_{\mathrm{st}}$ at EOI (denoted by the blue dashed vertical line) for which 5, 10 and $15 \mathrm{~s}^{-1}$ were chosen, the influence of which will be assessed. Trajectories of low- and high-T ignition in $\phi_{\mathrm{nC} 12}$-space are drawn for the three prescribed SDR scenarios. Note that for the same fuel injection event into an oxidizer charge with different methane contents, a comparable entrainment as well as SDR evolutions until high-T ignition are expected; the effect of temperature leads to a difference in density of only roughly $7 \%$. Therefore, we intentionally compare the two aforementioned cases exhibiting the same high-T ID making sure that the ignition processes experience as identical as possible small-/large-scale mixing histories in order to isolate the chemical effect of methane addition and its interaction with mixing.

Starting from $\mathrm{T}_{\mathrm{SOI}}=770 \mathrm{~K} / \phi_{\mathrm{CH} 4}=0$, as this is the more "standard" case similar to what is reported in $[10,13]$ : $\mathrm{CH}_{2} \mathrm{O}$ is first formed in the dodecane-lean region at around $0.6 \mathrm{~ms}$ and the species and heat generated are transported towards richer mixtures through micro-mixing (termed "cool-flame wave" in [11]). The typical time-scale of this process is approximately $0.2 \mathrm{~ms}$, consistent with the experiment, Figure 3 . Differently from what is reported in [10], here the coolflame wave is interrupted by the entrainment mixing because of the positive ignition dwell. The first high-T ignition 
takes place near $Z_{\max }$ where the mixture with the highest reactivity is present, following which the ignition front propagates towards leaner mixtures. As SDR at $Z_{\max }$ tends to zero, heat and radicals generated at the boundary are hardly mixed towards leaner conditions. Consequently, the propagation of the high- $\mathrm{T}$ ignition front is initially governed by a sequential high- $T$ transition moving from $Z_{\max }$ progressively to leaner states of mixing, corresponding to a localized ignition process where mixing is not important. At later stages the high- $\mathrm{T}$ front becomes progressively driven by diffusion because the SDR is larger in the central part of the $\mathrm{Z}$ existence domain. This is seen from the progressive deviation between results with different levels of prescribed SDR indicating that micro-mixing plays an important role later on. When advancing in time and approaching the $Z_{\min }$ boundary, the high-T ignition front slows down because of the lower reactivity and lower conditional SDR.

Examining the methane-containing case $\mathrm{T}_{\mathrm{SOI}}=850 \mathrm{~K} / \phi_{\mathrm{CH} 4}=0.66$ with similar high- $\mathrm{T}$ ID, differences are observed: Firstly, the $\phi_{\mathrm{nC} 12}$ location of the first $\mathrm{CH}_{2} \mathrm{O}$ appearance is at a higher value. This is to be expected when considering $\mathrm{HR}$ results (Figure 4 left). There is a "low-T most reactive $\phi_{\mathrm{nC} 12}$ " at around $\phi_{\mathrm{nC} 12}=0.6$, in distinctive contrast to the $\phi_{\mathrm{CH} 4}=0$ case. Consequently, when coupled to mixing, first-stage ignition takes place at around $\phi_{\mathrm{nC} 12}=0.5$ and, although the same SDR is present, the cool-flame wave propagates faster compared to the $\phi_{\mathrm{CH} 4}=0$ case. This is mainly attributed to the smaller low-T ID gradients in $\phi_{\mathrm{nC} 12}$-space from HR. This behavior is well-known from a series of auto-ignition DNS works in thermally and/or compositionally stratified mixtures, where the transition from spontaneous ignition to deflagrative combustion mode is mainly determined from gradients in homogeneous ID (e.g. [26]). Lower low-T ID gradients lead to a sequence of low-T ignition events where SDR plays a secondary role on the propagation speed. SDR has only a retarding effect on low-T ignition, as visible from the nearly parallel low-T ignition trajectories when varying SDR. This is in contrast to the $\phi_{\mathrm{CH} 4}=0$ case where a higher SDR leads to an increased propagation speed.

Despite the consistently retarded first appearance of $\mathrm{CH}_{2} \mathrm{O}$ when increasing SDR, for the diesel case the cool-flame wave is accelerated for increased SDR so that the high-T ignition takes place approximately at the same time, while for the dual-fuel case a delay in first $\mathrm{CH}_{2} \mathrm{O}$ results in also a delay of the first high- $\mathrm{T}$ ignition.

The dual-fuel high- $T$ ignition takes place at the $Z_{\max }$ boundary and the progress of the high-T ignition wave is slower than the one without methane. Another interesting feature observed during high-T ignition is that the dual-fuel case is more influenced by SDR compared to the diesel case, as confirmed by the different slopes with different SDR applied. This is attributed to the smaller $\mathrm{CH}_{2} \mathrm{O}$ consumption rate (a factor of 2-3 from HR, not shown) for dual-fuel during high-T ignition (visible from wider $\mathrm{CH}_{2} \mathrm{O}$ consumption wave in red), which makes the chemical reactions more susceptible to changes in mixing. 
It is stressed that the findings depend on the chemical mechanisms chosen: if a different relative influence of methane on the low-/high-T behaviors is predicted, this may change results drawn in Figure 4, however the systematic analysis of the main driving effects is still expected to apply.

\section{Summary and conclusions}

First and second-stage ignition characteristics of short $n$-dodecane pilot injection in compressed methane/air mixtures were investigated by application of simultaneous high-speed $\mathrm{CH}_{2} \mathrm{O}-\mathrm{PLIF}$, Schlieren and $\mathrm{OH}^{*}$ imaging in a RCEM. By systematic investigation of the methane interaction in the pilot-fuel ignition process we conclude that methane in the air charge prolongs the ID of pilot fuel through a chemical interaction - up to $50 \%$ increased ID in methane mixture with $\phi_{\mathrm{CH} 4}=0.66$ was observed. Comparison of the low- $\mathrm{T}$ and high-T ID for a variation of $\phi_{\mathrm{CH} 4}$ and $\mathrm{T}_{\mathrm{SOI}}$ shows that $70-80 \%$ of the ID prolongation is resulting from the delayed first-stage ignition. The evolution of $\mathrm{CH}_{2} \mathrm{O}-\mathrm{PLIF}$ distributions reveals a rapid spreading of the first-stage reactivity across the complete spray cloud. This so-called turbulent cool-flame wave reduces the first-stage ID of the fuel-rich mixture and therefore accelerates second-stage ignition in the fuel-rich zones.

Experimental observations were further substantiated by $0 \mathrm{D} / 1 \mathrm{D}$ simulations. HR calculations reveal, that unlike in $n$ dodecane/air mixtures with the addition of methane, not only high-T but also low-T ID becomes non-monotonic in $\phi_{\mathrm{nC} 12^{-}}$ space. Specifically, methane considerably retards low-T ignition at $n$-dodecane-lean conditions; first low- $T$ appearance occurs at $\phi_{\mathrm{nC} 12}=0.5$ whereas for the $n$-dodecane/air close to oxidizer boundary. This peculiarity is reflected in the $1 \mathrm{D}$ flamelet results with mixing: For both cases micro-mixing retards the first appearance of $\mathrm{CH}_{2} \mathrm{O}$. With methane, a faster cool-flame wave propagation is observed, which is due to smaller gradients in homogeneous low-T ID. The cool-flame spreading rate for the dual-fuel case was found to be less susceptible to variations in SDR, suggesting that the front is mainly governed by sequential low-T ignition, contrary to the prevalently micro-mixing governed diesel case cool-flame. Second-stage ignition occurs after the EOI for all investigated cases - consequently high-T ignition takes place at the instantaneously highest fuel concentration available. The subsequent high-T spreading on the contrary is slower for the dual-fuel case. It is important to note that the transition to a lean premixed flame was not the focus of this study.

In conclusion, the presented experimental and 0D/1D reveal a complex interplay between micro-mixing, low-T and high$\mathrm{T}$ chemistry and entrainment for dual-fuel auto-ignition processes. The non-monotonic low- $\mathrm{T}$ ID identified introduces an additional dynamic compared to previous investigations. This clearly motivates further investigations by means of highfidelity three-dimensional numerical methods in combination with state-of-the-art experimental diagnostics for further insights. 


\section{Acknowledgements}

Financial support from CCEM (project "ScheDual") and the Swiss Federal Office of Energy (grants SI/501123-01 and SI/501584-01) is gratefully acknowledged.

\section{References}

[1] J. Liu, F. Yang, H. Wang, M. Ouyang, S. Hao, Applied Energy, 110 (2013) 201-206.

[2] J. Rochussen, J. Yeo, P. Kirchen, SAE Technical Paper No. 2016-01-0792, (2016).

[3] N. Dronniou, J. Kashdan, B. Lecointe, K. Sauve, D. Soleri, SAE Int. J. Engines, 7 (2014) 873-887.

[4] K. Nithyanandan, Y. Gao, H. Wu, C.-F. Lee, F. Liu, J. Yan, SAE Technical Paper No. 2017-01-0755, (2017).

[5] E. Salaun, J. Apeloig, F. Grisch, C.-E. Yvonnet, B. Nicolas, F. Dionnet, SAE Technical Paper No. 2016-010772, (2016).

[6] S. Schlatter, B. Schneider, Y. Wright, K. Boulouchos, SAE Technical Paper No. 2012-01-0825, (2012).

[7] S. Schlatter, B. Schneider, Y.M. Wright, K. Boulouchos, Fuel, 179 (2016) 339-352.

[8] S.A. Skeen, J. Manin, L.M. Pickett, Proc. Combust. Inst., 35 (2015) 3167-3174.

[9] G. Borghesi, E. Mastorakos, R.S. Cant, Combust. Flame, (2013).

[10] A. Krisman, E.R. Hawkes, J.H. Chen, J. Fluid Mech., 824 (2017) 5-41.

[11] R.N. Dahms, G.A. Paczko, S.A. Skeen, L.M. Pickett, Proc. Combust. Inst., 36 (2017) 2615-2623.

[12] Z. Wang, J. Abraham, Proc. Combust. Inst., 35 (2015) 1041-1048.

[13] E. Demosthenous, G. Borghesi, E. Mastorakos, R.S. Cant, Combust. Flame, 163 (2016) 122-137.

[14] T. Kammermann, J. Koch, Y.M. Wright, P. Soltic, K. Boulouchos, SAE Int. J. Engines, 10 (2017).

[15] M. Bardi, R. Payri, L.M.C. Malbec, G. Bruneaux, L.M. Pickett, J. Manin, T. Bazyn, C.L. Genzale, Atomization Spray, 22 (2012) 807-842.

[16] S. Skeen, J. Manin, L.M. Pickett, SAE Int. J. Engines, 8 (2015) 696-715.

[17] P.C. Bakker, N. Maes, N. Dam, Combust. Flame, 182 (2017) 20-27.

[18] T. Lachaux, M.P.B. Musculus, Proc. Combust. Inst., 31 (2007) 2921-2929.

[19] L.M. Pickett, http://www.sandia.gov/ecn/dieselSprayCombustion.php, (2013).

[20] M.I. Najafabadi, L. Egelmeers, B. Somers, N. Deen, B. Johansson, N. Dam, Applied Physics B, 123 (2017).

[21] H. Pitsch, M. Chen, N. Peters, Proc. Combust. Inst., 27 (1998) 1057-1064. 
[22] E. Ranzi, A. Frassoldati, A. Stagni, M. Pelucchi, A. Cuoci, T. Faravelli, Int. J. Chem. Kinet., 46 (2014) $512-$ 542.

[23] M. Ghaderi Masouleh, A. Wehrfritz, O. Kaario, H. Kahila, V. Vuorinen, Fuel, 191 (2017) 62-76.

[24] S.S. Merchant, C.F. Goldsmith, A.G. Vandeputte, M.P. Burke, S.J. Klippenstein, W.H. Green, Combust. Flame, 162 (2015) 3658-3673.

[25] C.A. Idicheria, L.M. Pickett, Int. J. Engine Res., 12 (2011) 376-392.

[26] C.S. Yoo, T. Lu, J.H. Chen, C.K. Law, Combust. Flame, 158 (2011) 1727-1741. 